\title{
The Submissive Sex
}

\author{
Jacey Magnussen
}

Men hold power over women in almost every aspect of life; this is a historical and cross-cultural fact that becomes exemplified in heterosexual relationships. Males are expected to fulfill the role of provider and ruler while females take order and surrender emotional and physical care. Considering these roles and expectations, the unequal power dynamics within relationships often blur the lines of sexism and domination, often manifesting within sex as the fetishism of control. With a quick glance through Craigslist men seeking women personal ads, we are given a window into some of the fetishes expressed in heterosexual relationships:

"I am a 30 year old submissive male looking forward to being dominated and treated like a slave by a strict dominant mistress...I would do everything for my mistress and not limited to maintaining the house, cleaning...every household work and then be sexually tortured, tormented, humiliated and everything possible in my mistress's mind..." (Lookout for a dominant mistress, 2014) "I feel the most at peace when I'm kneeling at the feet of a woman and doing things to please her." (Submissive needing to serve dominant women, 2014)

Throughout this essay I will explore how public and historically pervasive gender roles effect one's sexual desires, specifically in regards to heterosexual men rejecting their positions in society and yearning to be controlled by dominant women. For this specific analysis I will be utilizing theory from second-wave feminism, a highly criticized but ultimately useful time for debates about sex. Sexual expression is a dynamic manifestation of people desires, but cannot be considered removed from one's environment and position in society. Additionally, it is worth noting that the tone of this essay is not anti-sex work, it is solely a critique of the desires of white, heterosexual, cis men and the means of attaining these desires. 
To begin, whether people are looking to take on the slave or master role there is obvious interest in testing power dynamics and either yielding total control or acquiring it. "Coitus can scarcely be said to take place in a vacuum; although of itself it appears a biological and physical activity, it is set so deeply within the larger context of human affairs that it serves as a charged microcosm of the variety of attitudes and values to which culture subscribes." (Millet, 1969) In other words, we can never remove our sexual interactions from the implications of our broader social environment and the ways in which we have been socialized.

Traditionally, males have held power over the female population in most facets of life - economically, institutionally, emotionally, and physically. People who are born female are socialized from birth to become submissive, gentle and obedient, while people who are born male are socialized to become the exact opposite - dominate, confident and in command. Due to this fact, many heterosexual relationships follow this pattern, with men as master and women as slave, both socially and sexually. "The sexual fantasy reported by psychoanalysis and that reported by pornography....associates sadism with the male ('the masculine role') and victimization with the female ('the feminine role')" (Millet, 1969, p. 48). Yet when a male chooses to submit sexually to a female it conflicts with our traditional gender roles, challenging the usual idea of men as sexually aggressive and possessive. Very rarely do we see males openly and voluntarily reducing their masculine role in society to submit to a female, either socially or sexually.

Theoretically, if the use of coercion or violence is not present within a personal relationship, power can only be attained if one relinquishes it to another. This consensual power may come about because of social norms associated with traditional heterosexual relationships and the effective socialization of females as subservient (Millet, 1969, p. 53), or for the desire to emulate the exact opposite of traditional male-dominated relationships. When men relinquish power within a sexual relationship, it is usually consensual and out of a desire to be controlled, to lose their patriarchal position, if only for a short while, and surrender total control to a female. Males in Western society are given a very narrow definition of masculinity to exist within, shying away from these macho expectations comes with certain consequences in one's everyday life - stigma, exclusion and even harassment and violence. However, abandoning these traits in the most private setting may be a safe 
and effective way to experience emancipation from this conventional role. The submissive male desires to be punished as a way to reduce anxiety and absolve masculine requirements, thereby making pain and feelings of domination pleasurable (Deleuze, 1971, p. 79).

"I need someone who is firm and experienced and won't hesitate to leave marks to get a message across. I'm a good person, but I need correction on occasion. For me, it's a form of stress outlet and an innate desire. It may sound strange but I find a sense of peace and clarity when sent to the corner..." (Wanted: experienced woman who spanks, 2014)

Upon corresponding with some of the men who post these ads on Craigslist they confirmed my theory of using this sexual outlet as a way to relinquish the power that is expected of them in everyday life.

"The release is probably being able to follow decisions instead of being looked to make decisions during my day job. Almost like the pendulum swinging the other way. As a man it seems that role of being the final say is [always] there." (personal communication, November 28, 2014) Power is not a definite or objective entity; power is an idea, one that can be played with. One who holds power in many aspects of life and considers this a burden to themselves may desire to relinquish it in a controlled setting, such as through sexual role playing. Additionally, if a person holds power in certain aspects of life, such as institutionally or financially, they have the ability to voluntarily relinquish power within other aspects of life, while the same cannot be said for one who lacks power within their social environment.

However, it does not follow that white, cis, heterosexual and able-bodied males should be seen as victims of their position in society. This sexual submission to women is voluntary and does not affect or influence one's privilege in other aspects of life. Society produces certain dynamics between genders whereby one group controls another (Millet, 1969, p. 37). “The military, industry, technology, universities, science, political office and finance - in short, every avenue of power within the society, including the coercive force of the police, is entirely in male hands" (Millet, 1969, p. 38). The privilege one is born with by virtue of being male cannot be reduced simply by the desire to do so. Many of these men 
see themselves as victims of their privilege; they want to shy away from the responsibilities they feel are delegated to them. Without the ability to dismiss these responsibilities in life, one must find an outlet in which to be controlled.

"A man's role is traditionally seen as one of strong and providing. That pressure seems to be what I shy away from and reject... I am in a leadership role, faced with daily decisions and actions that affect both my team and clients. Same for my personal life. Family and friends tend to fall to me for organizing or support in our dealings too. That role of power keeps coming to me and that in turn increases the urge to shy away or outlet that stress in a submissive manner." (personal communication, November 3, 2014)

Indeed, this is "a violence which arises only in connection with the choice and constitution of the fetish" (Deleuze, 1971, p. 29). That is to say, the varying degrees of violence associated with male's sexual slavery is that of a choice, it arises with allowance of a fetish, not out of a social condition in which the male is forced by way of social or economic dependence, as is the case with many females. One's personal choices within sex and relationships are heavily dependent on the context of the relationship and the factors constraining them. High social power and freedom in society also translate into power and freedom within personal interactions, allowing males greater freedom in sex and relationships.

Considering the fact that this sexual submission fantasy applies only to one very specific expression of obedience, it is arguable that even in this masochistic act heterosexual men are still objectifying and using women for their own pleasure. "Male domination of the female body is the basic material reality of women's lives" (Dworkin, 1981, p. 203). The female body is seen as the natural right of men and sex is used as a means of conquest and ownership (Dworkin, 1981, p. 203) whether or not the male is being physically possessive.

If so, to determine whether or not one is being objectified we may consider Nussbaum's features of objectification (1995), specifically instrumentality, fungibility and ownership. Instrumentality is the treatment of another as a tool for one's purposes (Nussbaum, 1995). In this case the submissive male searches out a female via Craigslist to 
fulfill his fantasy, feasibly, any female will do (fungibility being the interchangeableness of a person with any other person or object (Nussbaum, 1995)), so long as she satisfies his need to be controlled. Characteristically, sadism is said to be the violent and aggressive component of sexuality - the desire to take away another's freedom and independence. Typically masochism, being viewed as the opposite of sadism, is seen as the softer or more submissive reverse act, the act of relinquishing power (Deleuze, 1971, p. 90). However, the submissive still becomes possessive of the dominator by their desire to be absorbed by that person.

"I am a 59 year old, single, white male. I am very Submissive and ... I desperately need a new Mommy ... I am seeking a Lady who will decide what I wear, when and what I eat and when I am going to be put into bed. She would have full Control of me and decide what I will be aloud to do and how I must behave. Are you a Lady who would like to have a Adult male under your control, to decide everything for him and to make him endure Embarrassment and Humiliation at your hands, than message me and lets talk" (Sissy seeking a mommy, 2014).

The female master is still viewed as an object to have pleasure derived from (Delueze, 1971, p. 80), the female having to suspend all personal desires and devote entire focus to punishing and controlling the submissive male. On the surface we see a reversal of traditional gender roles yet this act is still inherently selfish on behalf of the male. One may imagine a masochist to suspend all personal desires and needs and exist only to please their master, desiring to become objectified themselves. Though this does not seem to be the case considering the demands made and the avenue in which these men are attempting to find women.

In conclusion, this is one way to look at the sexual fetish of male domination through a feminist lens, while focusing on the notion that sex does not exist outside of our patriarchal and fundamentally unequal society (Millet, 1969, p. 38). Through socialization, heterosexual relationships generally have an uneven power dynamic wherein the male controls the female simply by virtue of being born male (Millet, 1969, p. 38). Yet often times this birthright of power and dominance is seen as a burden. The masochistic male uses the female for the purposes of filling an unsatisfied role attempting to resolve guilt 
and experience sexual gratification (Deleuze, 1971, p. 124). However, this desire for a reversal of power does not negate the fact that in both personal relationships and the public sphere the sexualized image of women is created by and for heterosexual men, creating a vastly different reality for the each within sex. 
Works Cited

Deleuze, G. (1971). In George Braziller (Ed.), Masochism: An interpretation of coldness and cruelty. New York, NY: Faber and Faber Ltd.

Dworkin, A. (1981). Pornography: Men possessing women. University of Virgina: Putnam.

Foucault, M. (1976). The history of sexuality [Translated by Robert Hurley] Pantheon Books.

Lookout for a dominant mistress - 30. (2014, October 31). Retrieved from calgary.craigslist.ca/m4w/4739438283/html

Mill, J. S. (1869). The subjection of women. Feminist theory. A philosophical anthology. (pp. 17-26). Maldem, MA: Blackwell Publishing Ltd.

Millet, K. (1969). Sexual politics. Feminist theory. A philosophical anthology. (pp. 17-26). Maldem, MA: Blackwell Publishing Ltd.

Nussbaum, M. C. (1995). Objectification. Philosophy and Public Affairs, 24(4) Sissy seeking a mommy - 59. (2014, November 6). Retrieved from edmonton.craigslist.ca/m4w/4749310607.html

Submissive needing to serve dominant women - 27. (2014, October 15). Retrieved from calgary.craigslist.ca/m4w/4673734282.html

Wanted: experienced woman who spanks. (2014, November 6). Retrieved from calgary.craigslist.ca/m4w/4704327780.html 